\title{
Economic and stochastic efficiency analysis of alternative cover crop systems in Louisiana
}

\author{
Hua Wang ${ }^{1 \rtimes \star}$ (D), Naveen Adusumilli ${ }^{1}$, Donna Gentry ${ }^{2}$ and Lisa Fultz ${ }^{3}$ \\ ${ }^{1}$ Department of Agricultural Economics and Agribusiness, Louisiana State University Agricultural Center, Baton Rouge, \\ LA, USA, ${ }^{2}$ Southeast Region, Louisiana Master Farmer Program, Louisiana State University Agricultural Center, Baton \\ Rouge, LA, USA and ${ }^{3}$ School of Plant, Environmental and Soil Sciences, Louisiana State University Agricultural Center, \\ Baton Rouge, LA, USA \\ *Corresponding author. Email: hwang23@lsu.edu
}

(Received 30 January 2020; revised 20 May 2020; accepted 21 July 2020; first published online 30 September 2020)

\begin{abstract}
Summary
Landowners can engage in voluntary conservation with the help of incentive programs. Recommended conservation practices are selected based on management intentions as well as the contribution of those practices to the overall net returns. However, conservation motives are heterogeneous and based on individual risk behavior. Existing cost-share programs might either under-fund or over-fund conservation, which could lead to inefficient management of natural resources. The current analysis evaluates the economic feasibility of variable cover crop strategies, multiple seeding rates, within a soybean production system in silt loam and clay soils. The study utilizes stochastic efficiency with respect to a function, referred to as SERF, for determining the preferred strategies under various risk preferences. The SERF method accounts for the heterogeneity of individual decision-making with regards to conservation adoption. Results indicate that most risk-averse farmers chose tillage radish with medium seeding rate as their preferred strategy. However, as the risk-bearing capacity of an individual increases, the current level of incentives does not motivate to implement conservation. The most preferred plan for risk-neutral farmers is the fallow system in both silt loam and clay soils. The economic and risk assessment framework can improve understanding of the temporal dynamics of different practices and inform policy on conservation structure that promotes agricultural systems that are economically, environmentally, and socially sustainable.
\end{abstract}

Keywords: Cover crops; Net present value; Risk analysis; Certainty equivalent; Soybean

\section{Introduction}

Among agricultural conservation practices, integration of cover crops into annual crop rotations systems is a useful management option for maintaining and enhancing soil and water quality (Cavigelli et al., 2013; Lin, 2011). In recent years, interest in adding cover crops to cropping systems has increased as the potential benefits of cover crops have become more widely recognized. Cover crops offer a variety of benefits, including soil erosion control, increased biodiversity, nutrient recycling, increased soil organic matter, weed control, and increased crop yield (Adusumilli et al., 2016; Pimentel et al., 1995; Reddy et al., 2003; Sainju et al., 2002; Teasdale et al., 2007; Williams et al., 2009). The specific benefits of a cover crop also depend on the species and growing environment.

Field research has shown evidence of yield variation in cash crops following both single species and the mixture of cover crops (Burket et al., 1997), as well as when implemented in combination 
with other conservation practices; however, results varied across regions and within farms. Despite many advantages, cover crops can add new management challenges and risks. The decision to implement conservation practices, including cover crops, is significantly tied to economic factors related to on-farm production costs and barriers that interfere with cash crop demand (Adusumilli et al., 2019; Ashford and Reeves, 2003; Wortman et al., 2012).

Farmers can receive financial assistance from the Natural Resources Conservation Service (NRCS) for implementing a wide range of conservation practices, including cover crops. The NRCS will pay US $\$ 124$ to US $\$ 173$ per hectare to help farmers to try cover crops. Environmental Quality Incentives Program (EQIP) and Conservation Stewardship Program (CSP) are the two main programs that fund voluntary conservation. From 2005 to 2015, the US Department of Agriculture (USDA) funding for cover crops increased from about US\$5 million to US $\$ 56$ million. Although the acreage of cover crops has grown steadily over the last seven years, it accounts for only 5\% of the total crop area in the USA, according to the 2017 Census of Agriculture. Wade et al. (2015) suggested that program guidelines and profitability from using cover crops could help explain adoption patterns.

Louisiana is one of the three Delta states. The most recent National Resources Inventory report states that soil erosion in Louisiana is 4.93 tons per hectare per year (USDA, 2018). Conservation practices are widely promoted for addressing soil erosion in the state through working lands programs such as EQIP and CSP. Soybean acres are the highest among other row crop acres in Louisiana, currently at 486000 hectares (USDA National Agricultural Statistics Service (NASS), 2020). Thus, conservation practices such as cover crops, a high priority practice within the soil health agenda, evaluated within cash crops will help identify impacts of cover crops on net profits.

Cover crops are on the rise in Louisiana; however, they only account for less than $1 \%$ of cash crop acres. Farmers identify various challenges to low adoption within their farms. Some of the top concerns include NRCS program requirements, financial structure, and concerns over crop insurance. This analysis evaluates the financial structure that would improve adoption.

Both single species and mixed cover crops are promoted for providing the nutrient and soil benefits mentioned above. Marcillo and Miguez (2017), citing the potential of winter cover crops, suggested that incentives for winter cover crop adoption should consider factors beyond expectations for yield increase, such as improvements in nutrient cycling, water conservation, and erosion control. Single species are often popular among farmers due to the ease of planting, uniform development, and predictable termination efficacy of the cover crop, while mixtures may increase productivity, stability, resilience, and resource-use efficiency of the cover crop community (Mirsky et al., 2011; Rosario-Lebron et al., 2019; Tilman et al., 2001; Wortman et al., 2012).

Research has shown that cover crops affect crop yields differently (Anderson et al., 2020). In addition to the varied performance of these conservation practices in various production system niches, the perceived risk of these practices has also influenced farmers' adoption rates. In other words, risks associated with the tradeoffs between upfront investments, conservation benefits, and overall net returns often play a critical role in adoption decisions (Fathelrahman et al., 2011). As farmers differ in their risk behavior, comparison of net farm income from a set of management alternatives (e.g., cover crop, fertilizer management, surge valves for irrigation efficiency improvement, etc.) under general assumptions of the utility function can assist with incentives needed to adopt change.

Cover crop implementation requires additional field activities, which would incur costs to the farmers. Although cover crop practices have long-term benefits, in the short run, farmers would find it financially challenging to bear those costs. As a result, NRCS provides financial incentives for the first few years of implementation of cover crops. Moreover, NRCS programs receive funding levels based on priority resource concerns identified at the national level as well as at the state level. As the share of conservation funding for working land programs changes over time, the size and nature of the incentives might change, possibly affecting compliance incentives (Claassen et al. 2017). 
This research uses stochastic techniques for determining the most preferred cover crop system in Louisiana soybean production across a range of risk aversion preferences. As farmers often face many complex decisions, adding empirical values to augment understanding of management practices and the contribution of those practices to overall net farm benefits is warranted. An economic comparison accounting for risk and the total farm costs and returns using farm data enables an improved understanding of the tradeoffs between profitability and environmental protection. The results identify the risk premiums (RPs) - the minimum amount of incentives necessary to adopt cover crops. The 2018 Farm Bill suggests identifying high-priority practices and evaluating their financial assistance structure to improve adoption. The method used in this manuscript can provide a framework that accounts for the cost of the practice, the productivity of the following cash crop, and individual risk behavior in determining a more feasible financial incentive structure. Policymakers can find the results useful in assessing the level of funding necessary to promote these soil health programs and achieve desired conservation goals.

\section{Materials and Methods}

\section{Risk analysis}

Conservation of natural resources is critical for agricultural productivity. The adoption of conservation practices includes considering several factors that can add to the difficulty of producing a farming good. The individual's risk preferences determine the level of adoption as well as the choice for a conservation alternative(s). Risk assessment thus allows determining the preference for the set of outcomes by the decision-makers. Studies have used stochastic dominance methods for determining the decision-makers' attitude toward strategies that minimize agricultural risk. However, comparison of multiple alternatives is possible through stochastic efficiency with respect to a function (SERF) analysis (Adusumilli et al., 2020; Boyer et al., 2018; Fathelrahman et al., 2011; Khakbazan et al., 2017; Monjardino et al., 2013; Watkins et al., 2008; Williams et al., 2012).

The SERF method uses the concept of certainty equivalent (CE) for ranges of risk aversion levels as a selected measure of risk over a defined range. The CEs estimated can be defined as a specific payoff a decision-maker would require for changing his/her current practice (Hardaker et al., 2004). The SERF method allows for simultaneous comparison of alternatives based on CE values (Hardaker et al., 2004). The SERF method uses a utility function to estimate the CE values at each absolute risk aversion coefficient (ARAC). Proposed by Hardaker et al. (2004), the ARAC formula is used to calculate a decision-maker's degree of risk aversion. The ARAC values are calculated using the following method:

$$
A R A C_{w}=\frac{r_{r}(w)}{w}
$$

where $r_{r}(w)$ is the risk aversion coefficient for wealth $(w)$, and the value of $r_{r}(w)$ was set from zero to four (4), which means the decision-maker is risk neutral at $r_{r}(w)$ value equal to zero. Risk aversion increases as $r_{r}(w)$ value approach to four, as proposed by Anderson and Dillon (1992). Wealth $(w)$ was calculated as the respective mean net return for each of the cover crop practices under various seeding rates in the two different soil types.

Using the above formula, ARAC values estimated were in the range of $0.00-0.017$ and 0.00-0.031 for the silt loam and clay soil type, respectively. These ARAC values were used in the SERF analysis to calculate CE values. The SERF analysis was conducted in Simulation \& Econometrics to Analyze Risk (SIMETAR) (Richardson et al., 2003). Following Pendel et al. (2007), a negative exponential utility function was used in this analysis, which confirms the hypothesis that farmers prefer less risk to more given the same expected return.

The cover crops practice with the highest level of $\mathrm{CE}$ at a given level of risk aversion is the one that maximizes utility. The differences in CE values between any two alternatives will provide the utility weighted RP. The RP is the minimum amount of money (US $\$ \mathrm{ha}^{-1}$ in this study) an 
Table 1. Cover crop species and planting rates

\begin{tabular}{lccc}
\hline Species & Low rate $\left(\mathrm{kg} \mathrm{ha}^{-1}\right)$ & Medium rate $\left(\mathrm{kg} \mathrm{ha}^{-1}\right)$ & High rate $\left(\mathrm{kg} \mathrm{ha}^{-1}\right)$ \\
\hline Tillage radish & 7.9 & 11.2 & 14.6 \\
Crimson clover & 24.7 & 29.1 & 33.6 \\
Cereal rye & 62.8 & 98.6 & 134.5 \\
\hline
\end{tabular}

individual would need to justify a switch from a current production practice to another alternative. RPs determine the confidence of a decision-maker in a preferred alternative and are estimated using the following formula:

$$
R P_{A, B, r i}=C E_{A, r i(w)}-C E_{B, r i(w)}
$$

where $C E_{A, r i(w)}$ and $C E_{B, r i(w)}$ are the CEs of alternatives $A$ and $B$, respectively, at a given risk aversion level of $r_{i(w)}$, and $R P_{A, B, r i}$ is the resulting utility weighted RP. The RP's positive or negative value yields a measure of preference for one alternative over the other at a given risk aversion level. The $R P_{A, B, r i}$ is the minimum amount that a decision-maker would have to receive to switch from alternative A to alternative B under a specific risk aversion coefficient (Hardaker et al., 2004).

\section{Field experiment}

The field study was the basis for this analysis and conducted in central Louisiana during 2016-2018. Two soil types (Coushatta silt loam and Moreland clay) and three species with three seeding rates were used for the field experiment design. The seeding rates (Table 1) are classified as low, medium, and high, obtained from the USDA-NRCS. Planting date information was obtained from Texas and Alabama extension reports. Data were collected from the field experiments, which including 10 treatments (nine treatment combinations of species and seeding rates and an unplanted fallow) for a total of 60 plots $^{1}$. Three cover crop species were broadcast at each plot in Spring 2017 and Spring 2018 with soybean planted in Fall 2017 and Fall 2018. Before planting the cover crops, a routine soil test was conducted. Recommended fertilizer was applied. All field plots were planted to dryland soybean under conventional tillage before the cover crop plots were established. Rapides Parish (county) has an average of 220 days of growing season and is well suited for growing both cash crops and cover crops.

Cover crop species used in the study are crimson clover, cereal rye, and tillage radish. These species were selected based on our initial understanding that cereal rye provides winter cover, scavenges $\mathrm{N}$ after corn, becomes a long-lasting residue to hold moisture and suppresses weeds in cash crops. Crimson clover grows quickly to provide several cuttings for high-N green manure. Tillage radish is well suited to perform many valuable cover crop functions, provide soil cover, scavenge nutrients, suppress weeds, and alleviate compaction, while creating few of the residue management challenges associated with many other cover crops.

The field plots were established to quantify the impact of cover crop management practices on soybean production. The field experiments were implemented through a randomized complete block design with ten treatments and three blocks. Observed soybean yield data were from fields using the three cover crop species with low, medium, and high seeding rate combinations under each soil type followed by soybean (using a fallow control plot as a standard treatment). Before the termination of cover crops using herbicide application, biomass production was measured by taking hand clippings in one square meter in two different locations for each plot on the termination

\footnotetext{
${ }^{1}$ Are used for the analysis. The treatments are Crimson Clover, Cereal Rye, and Tillage Radish, each with low, medium, and high seeding rates, and fallow.
} 
Table 2. Summary statistics of soybean yield under silt loam soil scenario

\begin{tabular}{|c|c|c|c|c|}
\hline Production system & Mean $\left(\mathrm{kg} \mathrm{ha}^{-1}\right)$ & Standard deviation $\left(\mathrm{kg} \mathrm{ha}^{-1}\right)$ & Minimum $\left(\mathrm{kg} \mathrm{ha}^{-1}\right)$ & Maximum $\left(\mathrm{kg} \mathrm{ha}^{-1}\right)$ \\
\hline Crimson clover-low & $3265^{\mathrm{DE}}$ & 178 & 3069 & 3755 \\
\hline Crimson clover-medium & $3382^{C D}$ & 164 & 3185 & 3804 \\
\hline Crimson clover-high & $3317^{\mathrm{CD}}$ & 154 & 3126 & 3701 \\
\hline Cereal rye-low & $3503^{\mathrm{AB}}$ & 151 & 3306 & 3855 \\
\hline Cereal rye-medium & $3285^{\mathrm{DE}}$ & 232 & 3071 & 3983 \\
\hline Cereal rye-high & $3168^{\mathrm{E}}$ & 142 & 2988 & 3512 \\
\hline Tillage radish-low & $3416^{\mathrm{BC}}$ & 198 & 3207 & 3979 \\
\hline Tillage radish-medium & $3593^{A}$ & 139 & 3398 & 3872 \\
\hline Tillage radish-high & $2966^{F}$ & 212 & 2773 & 3605 \\
\hline Fallow & $3507^{A B}$ & 150 & 3310 & 3853 \\
\hline
\end{tabular}

Low, medium, and high indicate low, medium, and high seeding rates, respectively. Means in columns with differing superscripts are significantly different at least $p<0.05$ with respect to Fisher's LSD post hoc analyses.

date. Samples were dried in an oven, and dry matter production was determined. The plant material was analyzed to estimate nitrogen and carbon content.

\section{Simulation}

For the estimation of net returns, the variable costs of production and market price for soybean were obtained from the Louisiana State University Agricultural Center crop budgets (Deliberto et al., 2017). These reposts provide detailed information about the soybean production input. The direct expenses included seed, fertilizer and pesticides, labor, fuel for farm equipment and irrigation, repair and maintenance of farm equipment, depreciation, and interest. The average soybean price used in the estimation is US\$0.32 $\mathrm{kg}^{-1}$.

Crop prices, fuel, fertilizer, and yields were detrended using linear regression and residuals from the trend. Multivariate empirical (MVE) distributions of the variables were estimated and simulated using the excel add-in, SIMETAR, a simulation and an econometric tool used to analyze risk (Richardson et al. 2008). The MVE distribution provides the option to use limited historical data observations and can appropriately correlate random variables based on their historical correlation (Richardson et al., 2008). Parameters for the MVE include the means, deviations from the mean or trend expressed as a fraction of each variable, and the correlation among variables. The MVE distributions were used to simulate 1000 iterations of yields and prices. Net returns are estimated per hectare for the soybean production system based on the 1000 simulated iterations.

\section{Results and Discussion}

\section{Soybean yield}

The effect of cover crop on soybean yield was measured in each of the ten treatments (nine treatments with cover crops and one treatment with fallow) by harvesting ten plots per block. The average yield from three blocks for each treatment was calculated at $13.5 \%$ moisture content. Tables 2 and 3 provide the average soybean yield in silt loam and clay soils with different species and seeding rates, respectively. In silt loam soils, soybean yield ranged from 2966 to $3593 \mathrm{~kg} \mathrm{ha}^{-1}$ (Table 2). The highest mean soybean yield was $3593 \mathrm{~kg} \mathrm{ha}^{-1}$, with a standard deviation of 139 . While the highest mean soybean yield in clay soils was $3227 \mathrm{~kg} \mathrm{ha}^{-1}$ with a standard deviation of 106.

Analysis of variance was conducted to compare the means of yield for each of the cover crop practices under various seeding rates in both soil types using the SAS 9.4 program (SAS Institute Inc., Cary, NC, USA). Pairwise comparisons were made between the mean yield of fallow treatment 
Table 3. Summary statistics of soybean yield under clay soil scenario

\begin{tabular}{|c|c|c|c|c|}
\hline Production system & Mean $\left(\mathrm{kg} \mathrm{ha}^{-1}\right)$ & Standard deviation $\left(\mathrm{kg} \mathrm{ha}^{-1}\right)$ & Minimum $\left(\mathrm{kg} \mathrm{ha}^{-1}\right)$ & Maximum $\left(\mathrm{kg} \mathrm{ha}^{-1}\right)$ \\
\hline Crimson clover-low & $3227^{A}$ & 106 & 3046 & 3395 \\
\hline Crimson clover-medium & $3189^{\mathrm{AB}}$ & 104 & 3009 & 3354 \\
\hline Crimson clover-high & $3074^{\mathrm{CD}}$ & 100 & 2901 & 3233 \\
\hline Cereal rye-low & $2847^{\mathrm{E}}$ & 93 & 2687 & 2994 \\
\hline Cereal rye-medium & $3079^{C D}$ & 101 & 2905 & 3238 \\
\hline Cereal rye-high & $3104^{C D}$ & 102 & 2929 & 3264 \\
\hline Tillage radish-low & $3042^{\mathrm{D}}$ & 100 & 2872 & 3200 \\
\hline Tillage radish-medium & $3149^{B C}$ & 103 & 2971 & 3311 \\
\hline Tillage radish-high & $3124^{\mathrm{BC}}$ & 102 & 2948 & 3286 \\
\hline Fallow & $3083^{\mathrm{CD}}$ & 101 & 2909 & 3243 \\
\hline
\end{tabular}

Low, medium, and high indicate for low, medium, and high seeding rates, respectively. Means in columns with differing superscripts are significantly different at least $p<0.05$ with respect to Fisher's LSD post hoc analyses.

and alternative cover crop systems using Fisher's protected LSD at the 5\% significant level (Tables 2 and 3). The Least Significant Difference (LSD) tests found fewer significant differences between fallow treatment and the three cover crop species with variable seeding rates treatments in the clay soils than the silt loam soils. In the silt loam soils, the mean yield under fallow treatment was significantly different from the mean yields under all crimson clover treatments, cereal rye with high and medium seeding rate treatments, and tillage radish with high seeding rate treatment. While in the clay soils, the mean yield under fallow treatment is significantly different from the mean yields under crimson clover with low and medium seeding rates and cereal rye with a low seeding rate.

\section{Economic and risk analysis}

The net return estimates are presented in Table 4. In the silt loam soils, the tillage radish-medium, cereal rye-low, and tillage radish-low are the three most profitable cover crop strategies. Meanwhile, tillage radish-medium, crimson clover-low, and tillage radish-high practices are the three most profitable cover crop strategies in the clay scenario. The fallow treatment had the highest net return per hectare, which is due to not having any cover crop planting, management, and termination costs.

The net return analysis is used to estimate the CE values for each of the cover crop alternatives in both soil types using the SERF framework. The corresponding RP values to shift from a fallow system to a cover crop alternative are calculated. The results under each soil type, silt loam, and clay are presented in Tables 5 and 6, respectively. A risk-neutral farmer (profit maximizer) having silt loam soils would need at least US\$69 $\mathrm{ha}^{-1}$ to shift from the current practice of the fallow system to tillage radish with a medium seeding rate, the most profitable cover crop alternative. As there are no additional costs associated with having the ground fallow, a farmer would need some incentive to cover the cost of seed and herbicides for management and termination of cover crop.

It is important to note that for the profit-maximizing farmer, the premium to shift from fallow to a cover crop with medium seeding rate is lower than the premium required to change from fallow to a cover crop with low seeding rate. This result here is quite intuitive. One of the primary purposes of the cover crop is to provide biomass, which contributes to organic matter development in the soil. The farmer intending to shift from fallow would like to maximize the benefits of having a cover crop on the ground. Thus, the farmer would implement a practice that would provide the most biomass, vis-a-vis, most net profits, US\$328 ha-1 - also referred to as the CE for the risk-neutral (profit-maximizing) farmer. With the estimation of CEs, one can identify the level of premiums (financial incentives) needed to shift from current practice to any other conservation 
Table 4. Summary statistics of simulated net returns under silt loam and clay soil scenarios

\begin{tabular}{lcccc}
\hline & \multicolumn{2}{c}{ Silt loam soil $\left(\right.$ US\$ ha $\left.{ }^{-1}\right)$} & \multicolumn{2}{c}{ Clay soil (US\$ ha h $\left.^{-1}\right)$} \\
\cline { 2 - 3 } Production system & Mean & Standard deviation & Mean & Standard deviation \\
\hline Crimson clover-low & 189 & 114 & 146 & 72 \\
Crimson clover-medium & 213 & 110 & 122 & 69 \\
Crimson clover-high & 179 & 103 & 74 & 65 \\
Cereal rye-low & 290 & 112 & 57 & 63 \\
Cereal rye-medium & 224 & 140 & 128 & 70 \\
Cereal rye-high & 162 & 97 & 113 & 68 \\
Tillage radish-low & 283 & 133 & 136 & 71 \\
Tillage radish-medium & 328 & 110 & 142 & 71 \\
Tillage radish-high & 124 & 124 & 234 & 82 \\
Fallow & 396 & 126 & & \\
\hline
\end{tabular}

Low, medium, and high stand for low, medium, and high seeding rates, respectively.

Table 5. Certainty equivalents of dominant cover crop strategies and risk premiums of the fallow strategy relative to dominant cover crop strategies across absolute risk aversion coefficients under the silt loam soil scenario

\begin{tabular}{|c|c|c|c|c|}
\hline & \multicolumn{4}{|c|}{ Absolute risk aversion coefficients } \\
\hline & 0.000 & 0.005 & 0.011 & 0.017 \\
\hline & Risk neutral (profit maximizer) & & & risk averse \\
\hline \multicolumn{5}{|c|}{ Certainty equivalents (US\$ ha ${ }^{-1}$ ) } \\
\hline Cereal rye-low & 290 & 260 & 225 & 186 \\
\hline Tillage radish-low & 283 & 241 & 192 & 140 \\
\hline Tillage radish-medium & 328 & 298 & 265 & 227 \\
\hline \multirow[t]{2}{*}{ Fallow } & 396 & 357 & 313 & 265 \\
\hline & \multicolumn{4}{|c|}{ Risk premiums (US\$ ha ${ }^{-1}$ ); asking to shift from fallow } \\
\hline Cereal rye-low & 106 & 98 & 89 & 80 \\
\hline Tillage radish-low & 113 & 117 & 121 & 126 \\
\hline Tillage radish-medium & 69 & 59 & 49 & 38 \\
\hline
\end{tabular}

Low and medium stand for low and medium seeding rates, respectively.

Table 6. Certainty equivalents of dominant cover crop strategies and risk premiums of the fallow strategy relative to dominant cover crop strategies across absolute risk aversion coefficients under the clay soil scenario

\begin{tabular}{|c|c|c|c|c|}
\hline & \multicolumn{4}{|c|}{ Absolute risk aversion coefficients } \\
\hline & 0.000 & 0.009 & 0.019 & 0.031 \\
\hline & Risk neutral (profit maximizer) & & & risk averse \\
\hline \multicolumn{5}{|c|}{ Certainty equivalents (US\$ ha ${ }^{-1}$ ) } \\
\hline Crimson clover-low & 146 & 123 & 97 & 70 \\
\hline Tillage radish-high & 142 & 119 & 94 & 65 \\
\hline Tillage radish-medium & 159 & 135 & 108 & 78 \\
\hline \multirow[t]{2}{*}{ Fallow } & 234 & 204 & 170 & 134 \\
\hline & \multicolumn{4}{|c|}{ Risk premiums (US\$ ha ${ }^{-1}$ ); asking to shift from fallow } \\
\hline Crimson clover-low & 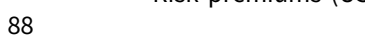 & 81 & 72 & 64 \\
\hline Tillage radish-high & 92 & 85 & 76 & 69 \\
\hline Tillage radish-medium & 75 & 69 & 62 & 56 \\
\hline
\end{tabular}

Low, medium, and high stand for low, medium, and high seeding rates, respectively.

measure. The current practice does not necessarily have to be a fallow system but any other conservation alternative with relatively lower net benefits.

The RP for implementing tillage radish cover crop with medium seeding rate for more riskaverse farmers indicated by ARAC values becoming more positive is US $\$ 38 \mathrm{ha}^{-1}$. This result 

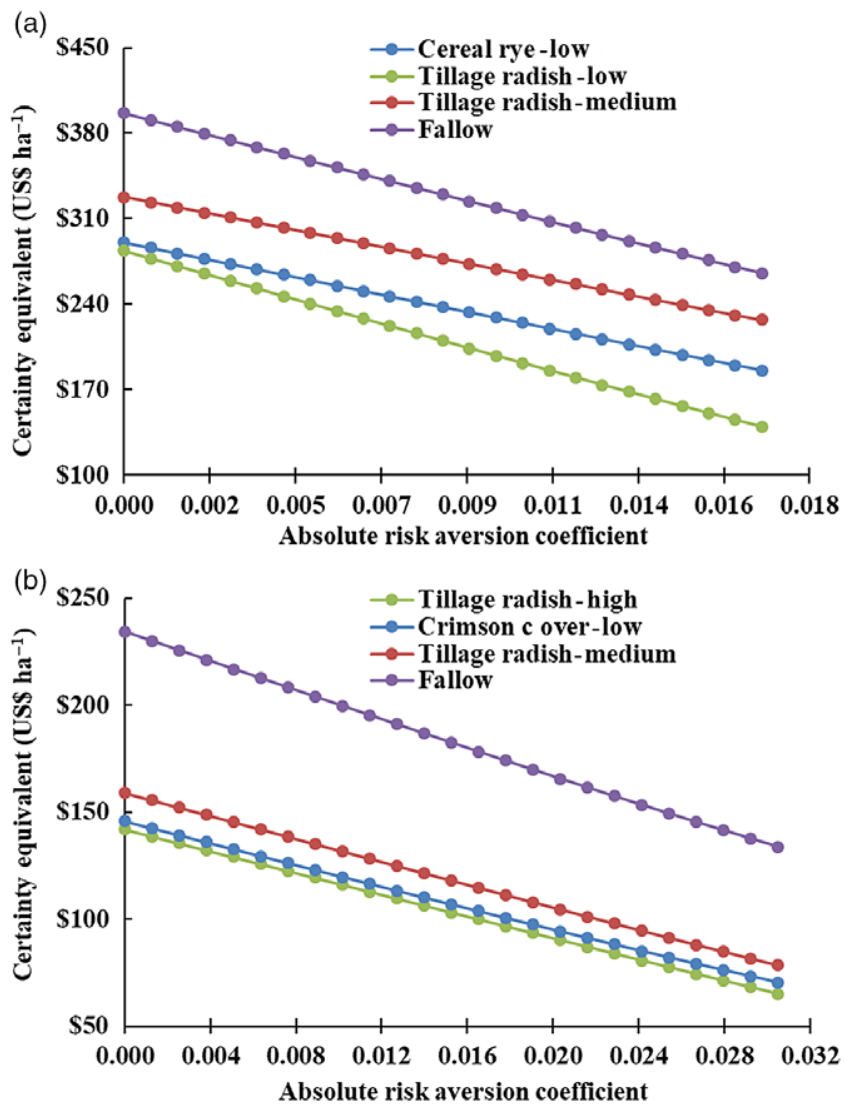

Figure 1. Stochastic efficiency with respect to a function estimated certainty equivalents for (a) silt loam soil type and (b) clay soil type using different cover crops and seeding rates.

indicates that as farmers become aware of the impacts such as loss of soil productivity due to natural and human activities, their intent to implement conservation practices is higher and requires relatively lower incentives to adopt conservation alternative(s). The only exception in the alternatives evaluated is tillage radish-low, where a risk-neutral farmer needs as high as US $\$ 113 \mathrm{ha}^{-1}$ to shift from a fallow system. However, for more risk-averse farmers, the premium to change from fallow is higher because the immediate net returns are lower in this system. Hence, risk-averse farmers, if presented with this alternative, require a higher premium to shift to compensate for any potential losses to net returns.

The presence of cover crop biomass influences soil moisture content differently in silt loam soils versus clay soils, consequently affecting nutrient movement in those soils. However, the profitable cover crop strategy is tillage radish-medium in both soil types as it provided the optimal ground cover. The results from clay soil type are consistent with economic theory. Risk-neutral farmers need higher premiums to shift to a conservation alternative. More risk-averse farmers need lower premiums. For the same conservation alternative, tillage radish with medium seeding rate, the premium to shift from fallow is slightly higher, US $\$ 75 \mathrm{ha}^{-1}$, than that in silt loam soils. The premiums decrease for more risk-averse farmers. The other top two alternatives are tillage radish with a high seeding rate and crimson clover with a low seeding rate. The CEs per hectare for the most profitable alternatives over the full range of ARAC values in silt loam and clay soils are presented in Figure 1a and 1b, respectively. The fallow treatment is the most preferred production strategy in both soil scenarios. The dominant cover crop strategy for silt loam soils (Figure 1) and 
clay soils (Figure $1 \mathrm{~b}$ ) is tillage radish-medium. The results show that the financial incentive farmers anticipate is lowest, across all levels of risk aversion, to shift from fallow to tillage radish-medium. However, NRCS cost-share assistance for cover crops takes only into account the cost to implement cover crops as a conservation strategy, irrespective of soil type, species type, and risk tolerance level of the farmer. If NRCS deems all three cover crop strategies as equally beneficial for the environment, then the financial incentives (RPs) for producers to switch from the fallow strategy to the tillage radish-medium strategy would be the smallest relative to the other cover crop strategies evaluated. However, if the NRCS feels there is a better strategy for the environment than the tillage radish-medium strategy, they would need to provide greater financial incentives to producers to use the more environmentally sound strategy, and this is more evident in silt loam soils than for clay soils based on the results of this study.

The conservation incentives provided by the NRCS for cover crop strategies are in the range of US $\$ 100$ to $\$ 140 \mathrm{ha}^{-1}$, for implementing single species and multiple species of cover crops, respectively. At the same time, farmers are allowed to stack conservation practices, that is, implement other conservation practices with cover crops and take advantage of cost-share payments for those additional practices. However, it is essential to account for the heterogeneity of individual decision-making, mostly based on their risk-bearing potential. Supporting landowners with resources may encourage initial participation as well as sustain continued conservation after exiting the program (Lutter et al., 2019).

Our findings add to the existing literature that risk plays a vital role in conservation decisionmaking (Boyer et al., 2018; Watkins et al., 2008). The analysis provides a technical understanding of creating a conservation incentive structure that is not solely based on the cost of implementation of practice but also the achievement of economically efficient conservation goals. An efficient conservation structure can extend the benefits of the program either by evaluating conservation payments necessary to motivate change or by continuing the cost-share payments beyond the current limits of three to five years. Past research has shown that reduction in soil erosion on working lands, consequently production, will likely prevent bringing marginal lands back to production (Skaggs et al., 1994).

Cover crops practices funded through EQIP and CSP represent one of the many conservation practices, but our findings have implications in the broader context of national conservation goals. First, assuming that individuals respond equally to the cost-share structure could be detrimental to conservation efforts, as this would not produce expected conservation gains, which we found in this study. As landowners do not respond uniformly to incentive structures, coupled with some of the uncertainty with the performance of management practices, incentives for conservation practices play a significant role in securing long-term conservation engagement (Selinske et al., 2016). An incentive payment design focused on an appropriate structure that accounts for heterogeneity in individual decision-making could bolster program enrollment.

\section{Conclusions}

This study presents an evaluation of the conservation incentive structure of popular programs using a risk analysis framework, the SERF. The SERF framework is utilized to estimate CE and $\mathrm{RP}$ values. The latter indicates the minimum incentive needed to motivate a change from current practice to the next best conservation alternative. These values differ based on the risk profile of farmers. Risk analysis shows that the tillage radish-medium, tillage radish-low, and cereal rye-low are the preferred strategies in silt loam soils. In contrast, tillage radish-medium, tillage radish-high, and crimson clover-low are the preferred strategies in clay soils. The analysis also shows that the minimum amount for a profit-maximizing farmer to shift from a fallow system to a cover crop alternative is US $\$ 69$ and US $\$ 75 \mathrm{ha}^{-1}$ in silt loam and clay soils, respectively. Finally, from the analysis, it is evident that the premiums required to motivate change are lower for risk-averse farmers. 
The NRCS provides cost-share assistance to farmers for voluntary implementation of conservation practices for addressing soil erosion, water quality, water quantity, nutrient loss, etc. The NRCS programs are often in deliberation for funding levels, which significantly affects conservation implementation. RPs indicate the level of funding necessary to motivate a change from farmer standard practices to enhanced conservation. As a result, conservationists and policymakers can benefit from updated information and funding levels required to achieve environmental goals.

Although the estimation of the results in this study is based on two years of field research in Louisiana, the results can be applied to other regions for evaluating conservation programs and payment structures. As billions of dollars are allocated to fund conservation practice implementation, it is essential to assess decision-making under risk using farm-level data whenever available.

Acknowledgements. The authors would like to thank the NRCS leadership and research station staff who supported the program through suggestions and discussions. The opinions are those of the authors and do not reflect the views of the organizations that they represent.

Conflict of interest. The authors declare no conflict of interest.

\section{References}

Adusumilli N., Davis S. and Fromme D. (2016). Economic evaluation of using surge valves in furrow irrigation of row crops in Louisiana: a net present value approach. Agricultural Water Management 174, 61-65.

Adusumilli N., Dikitanan R. and Wang H. (2019). Effect of cost-sharing federal programs on adoption of water conservation practices: results from propensity score matching approach. Water Economics and Policy, 1950004.

Adusumilli N., Wang H., Dodla S. and Deliberto M. (2020). Estimating risk premiums for adopting no-till and cover crops management practices in soybean production system using stochastic efficiency approach. Agricultural Systems 178, 102744 .

Anderson J.R. and Dillon J.L. (1992). Risk analysis in dryland farming systems (No. 2). Food and Agriculture Organization.

Anderson A.E., Hammac W.A., Stott D.E. and Tyner W.E. (2020). An analysis of yield variation under soil conservation practices. Journal of Soil and Water Conservation 75, 103-111.

Ashford D.L. and Reeves D.W. (2003). Use of a mechanical roller-crimper as an alternative kill method for cover crops. American Journal of Alternative Agriculture 18, 3745.

Boyer C.N., Lambert D.M., Larson J.A. and Tyler D.D. (2018). Investment analysis of cover crop and no-tillage systems on Tennessee cotton. Agronomy Journal 110 331-338.

Cavigelli M.A., Mirsky S.B., Teasdale J.R., Spargo J.T. and Doran J. (2013). Organic grain cropping systems to enhance ecosystem services. Renewable Agriculture and Food Systems 28, 145-159.

Burket J.Z., Hemphill D.D. and Dick R.P. (1997). Winter cover crops and nitrogen management in sweet corn and broccoli rotations. HortScience 32, 664-668.

Claassen R.L., Bowman M., Breneman V., Wade T., Williams R., Fooks J., Hansen L., Iovanna R. and Loesch C. (2017). Conservation Compliance: How Farmer Incentives are Changing in the Crop Insurance Era. United States Department of Agriculture, Economic Research Service.

Deliberto M.A., Salassi M.E. and Hilbun B.M. (2017). Projected Costs and Returns Crop Enterprise Budgets for Soybean Production in Louisiana, 2017. Louisiana State University Agricultural Center.

Fathelrahman E.M., Ascough J.C., Hoag D.L., Malone R.W., Heilman P., Wiles L.J. and Kanwar R.S. (2011). Economic and stochastic efficiency comparison of experimental tillage systems in corn and soybean under risk. Experimental Agriculture 47, 111-136.

Hardaker J.B., Richardson J.W., Lien G. and Schumann K.D. (2004). Stochastic efficiency analysis with risk aversion bounds: A simplified approach. Australian Journal of Agricultural and Resource Economics 48, 253-270.

Khakbazan M., Larney F.J., Huang J., Mohr R.M., Pearson D.C. and Blackshaw R.E. (2017). Economics of conventional and conservation practices for irrigated dry bean rotations in southern Alberta. Agronomy Journal 109, 576-587.

Lin B.B. (2011). Resilience in agriculture through crop diversification: adaptive management for environmental change. BioScience 61, 183-193.

Lutter S.H., Dayer A.A. and Larkin J.L. (2019). Young forest conservation incentive programs: explaining re-enrollment and post-program persistence. Environmental Management 63, 270-281.

Mallory E.B., Posner J.L. and Baldock J.O. (1998). Performance, economics and adoption of cover crops in Wisconsin cash grain rotations: on-farm trials. American Journal of Alternative Agriculture 13, 211. 
Marcillo G.S. and Miguez F.E. (2017). Corn yield response to winter cover crops: an updated meta-analysis. Journal of Soil and Water Conservation 72, 226-239.

Mirsky S.B., Curran W.S., Mortenseny D.M., Ryany M.R. and Shumway D.L. (2011). Timing of cover-crop management effects on weed suppression in no-till planted soybean using a roller-crimper. Weed Science 59, 380-389.

Monjardino M., McBeath T.M., Brennan L. and Llewellyn R.S. (2013). Are farmers in low-rainfall cropping regions underfertilising with nitrogen? A risk analysis. Agricultural Systems 116, 37-51.

Pendell D.L., Williams J.R., Boyles S.B., Rice C.W. and Nelson R.G. (2007). Soil carbon sequestration strategies with alternative tillage and nitrogen sources under risk. Review of Agricultural Economics 29, 247-268.

Pimentel D., Harvey C., Resosudarmo P., Sinclair K., Kurz D., McNair M., Crist S., Shpritz L., Fitton L., Saffouri R. and Blair R. (1995). Environmental and economic costs of soil erosion and conservation benefits. Science 267, 1117-1123.

Ramos M.E., Benítez E., García P.A. and Robles A.B. (2010). Cover crops under different managements vs. frequent tillage in almond orchards in semiarid conditions: effects on soil quality. Applied Soil Ecology 44, 6-14.

Reddy K.N., Zablotowicz R.M., Locke M.A. and Koger C.H. (2003). Cover crop, tillage, and herbicide effects on weeds, soil properties, microbial populations, and soybean yield. Weed Science 51, 987-994.

Reeves D.W. (1994). Cover crops and rotations. In Hatfield L. and Stewart B.A. (eds.) Advances in Agronomy. Crop Residue Management, pp. 125-172. Boca Raton, FL: CRC Press.

Richardson J.W., Feldman P. and Schuemann K. (2003). Simetar ${ }^{\mathrm{Tw}}$. College Station, TX: Department of Agricultural Economics, Texas A\&M University.

Richardson J.W., Schuemann K. and Feldman P. (2008). Simetar: Simulation and econometrics to analyze risk. College Station. College Station, TX: Department of Agricultural Economics, Texas A\&M University.

Rosario-Lebron A., Leslie A.W., Yurchak V.L., Chen G. and Hooks C.R. (2019). Can winter cover crop termination practices impact weed suppression, soil moisture, and yield in no-till soybean [Glycine max (L.) Merr.]. Crop Protection 116, 132-141.

Sainju U., Singh B. and Whitehead W. (2002). Long-term effects of tillage, cover crops, and nitrogen fertilization on organic carbon and nitrogen concentrations in sandy loam soils in Georgia, USA. Soil and Tillage Research 63, $167-179$.

Selinske M.J., Cooke B., Torabi N., Hardy M.J., Knight A.T. and Bekessy S.K. (2016). Locating financial incentives among diverse motivations for long-term private land conservation. Ecology and Society 22, 7.

Skaggs R.K., Kirksey R.E. and Harper W.M. (1994). Determinants and implications of post-crop land-use decisions. Journal of Agricultural and Resource Economics 19, 299-312.

Teasdale J.R., Brandsaeter L.O., Calegari A., Neto F.S., Upadhyaya M.K. and Blackshaw R.E. (2007). Cover crops and weed management. In Upadhyaya MK and Blackshaw RE (eds.) Non-Chemical Weed Management: Principles, Concepts and Technology, pp. 49-64.

Tilman D., Reich P.B., Knops J., Wedin D., Mielke T. and Lehman C. (2001). Diversity and productivity in a long-term grassland experiment. Science (Washington, DC) 294, 843-845.

U.S. Department of Agriculture. (2018). Summary Report: 2015 National Resources Inventory, Natural Resources Conservation Service, Washington, DC, and Center for Survey Statistics and Methodology, Iowa State University, Ames, Iowa.

U. S. Department of Agriculture, National Agricultural Statistics Service. (2020). Louisiana Soybean Acreage Estimates. Washington, DC.

Watkins K., Hill J. and Anders M. (2008). An economic risk analysis of no-till management and rental arrangements in Arkansas rice production. Journal of Soil and Water Conservation 63, 242-250.

Wade T., Claassen R. and Wallander S. (2015). Conservation-practice adoption rates vary widely by crop and region. U.S. Department of Agriculture-Economic Research Service EIB-147.

Williams J.D., Gollany H.T., Siemens M.C., Wuest S.B. and Long D.S. (2009). Comparison of runoff, soil erosion, and winter wheat yields from no-till and inversion tillage production systems in northeastern Oregon. Journal of Soil and Water Conservation 64, 43-52.

Williams J.R., Pachta M.J., Roozeboom K.L., Llewelyn R.V., Claassen M.M. and Bergtold J.S. (2012). Risk analysis of tillage and crop rotation alternatives with winter wheat. Journal of Agricultural and Applied Economics 44, 561-576.

Wortman S.E., Francis C.A., Bernards M.L., Drijber R.A. and Lindquist J.L. (2012). Optimizing cover crop benefits with diverse mixtures and an alternative termination method. Agronomy Journal 104, 1425-1435.

Wortman S.E. (2015). Crop physiological response to nutrient solution electrical conductivity and $\mathrm{pH}$ in an ebb-and-flow hydroponic system. Scientia Horticulturae 194, 34-42.

Cite this article: Wang H, Adusumilli N, Gentry D, and Fultz L (2020). Economic and stochastic efficiency analysis of alternative cover crop systems in Louisiana. Experimental Agriculture 56, 651-661. https://doi.org/10.1017/ S0014479720000216 